\title{
Impacto de fatores associados à sintomatologia depressiva na saúde de idosos após mudança habitacional
}

\author{
Impact of factors associated with depression symptoms on older adults' health \\ after moving house
}

\section{Impacto de factores asociados con la sintomatología de depresión en la salud de mayores después del cambio habitacional}

\author{
Jovelina Fernandes dos Santos (iD \\ Universidade Federal de Campina Grande - Cajazeiras (PB) - Brasil \\ Mayara Evangelista de Andrade iD \\ Universidade Federal de Campina Grande - Cajazeiras (PB) - Brasil \\ Joyce Wadna Rodrigues de Souza iD \\ Universidade Federal de Campina Grande - Cajazeiras (PB) - Brasil
}

Ariane Moreira Coelho (iD)

Universidade Federal de Campina Grande - Cajazeiras (PB) - Brasil

Petra Kelly Rabelo de Sousa Fernandes

Centro Universitário Fametro - Fortaleza (CE) - Brasil

Marcelo Costa Fernandes (iD

Universidade Federal de Campina Grande - Cajazeiras (PB) - Brasil

\section{RESUMO}

Objetivo: Conhecer as dificuldades que o idoso apresenta após mudança de moradia e que influenciam para os sintomas de depressão. Métodos: Estudo descritivo, com abordagem qualitativa, realizado com 14 idosos, em 2018, residentes em um conjunto habitacional para idosos localizado na cidade de Cajazeiras, Paraíba, Brasil. Empregou-se entrevista semiestruturada para a coleta de dados, sendo os depoimentos decompostos e organizados por meio do processo metodológico do Discurso do Sujeito Coletivo, emergindo três ideias centrais, descritas a seguir: conflitos familiares; dificuldade nas relações interpessoais e isolamento social como desencadeador da depressão. Resultados: Os participantes desta pesquisa possuem uma rede social escassa e poucas relações significativas. Além disso, retratam dificuldades nas relações interpessoais e conflitos com seus familiares. Conclusão: No presente estudo, pode-se ver sentimentos que podem resultar no surgimento da sintomatologia depressiva, como sentimento de solidão, dificuldades de convivência e isolamento social, apesar do programa habitacional oferecer assistência à saúde e espaços de convivência para a interação social e lazer.

Descritores: Depressão; Assistência Integral à Saúde; Idoso.

\section{ABSTRACT}

Objective: To know the difficulties faced by older adults after moving house that influence depression symptoms. Methods: This qualitative descriptive study was carried out in 2018 with 14 older adults living in a housing complex for older adults located in the city of Cajazeiras, Paraíba, Brazil. Semi-structured interviews were used to collect data and the accounts were decomposed and organized following the Collective Subject Discourse methodological process, which resulted in the emergence of three core ideas as follows: family conflicts; difficulties in interpersonal relationships; and social isolation as a trigger of depression. Results: The research participants had poor social networks and few meaningful relationships. In addition, they reported difficulties in interpersonal relationships and conflicts with their families. Conclusion: The present study revealed feelings that can result in the onset of depression symptoms, such as feelings of loneliness, difficulties in co-living, and social isolation, although the housing program offers health care and spaces for social interaction and leisure.

Descriptors: Depression; Comprehensive Health Care; Aged.

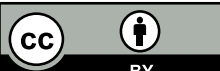




\section{RESUMEN}

Objetivo: Conocer las dificultades de la persona mayor después del cambio de vivienda que influyen en los síntomas de la depresión. Métodos: Estudio descriptivo, de abordaje cualitativo realizado en 2018 con 14 mayores que vivian en un conjunto habitacional para mayores localizado en la ciudad de Cajazeiras, Paraíba, Brasil. Para la recogida de datos se ha realizado la entrevista semiestructurada y los relatos han sido organizados a través del proceso metodológico del Discurso del Sujeto Colectivo del cual ha emergido tres ideas centrales que están descritas a continuación: conflictos familiares; dificultad de las relaciones interpersonales y aislamiento social como el provocador de la depresión. Resultados: Los participantes de la investigación tienen una red social escasa y pocas relaciones significativas. Además, retratan dificultades de las relaciones interpersonales y conflictos con sus familiares. Conclusión: En el presente estudio se puede ver los sentimientos que pueden resultar en la aparición de la sintomatología de la depresión como el sentimiento de la soledad, las dificultades de convivencia y el aislamiento social pese a que el programa habitacional ofrezca la atención a la salud y espacios de convivencia para la interacción social y el ocio.

Descriptores: Depresión; Atención Integral de Salud; Anciano.

\section{INTRODUÇÃO}

O envelhecimento populacional vem ocorrendo como fenômeno mundial. No Brasil, nas últimas décadas, houve um crescimento expressivo do número de idosos devido ao aumento da longevidade e a redução das taxas de fertilidade e mortalidade. O país atualmente conta com 16 milhões de indivíduos com 60 anos ou mais, número que passará a 32 milhões em $2025^{(1)}$. As estimativas preveem que, nesse mesmo ano, o Brasil seja o sexto país com a maior quantidade de pessoas idosas no mundo(2).

O processo de envelhecimento pode estar associado ao declínio funcional e cognitivo, à perda da autonomia e independência, à diminuição significativa do vigor físico e da sensação de produtividade, e todos esses fatores tornam os idosos propensos à depressão. A depressão pode levar as pessoas idosas ao questionamento do significado da vida e à perda do interesse pelas atividades diárias, afetando diretamente sua saúde física e emocional. Essa doença é muitas vezes negligenciada pelos profissionais de saúde devido à associação dos sintomas depressivos com manifestações fisiológicas da senescência ${ }^{(3,4)}$.

A depressão caracteriza-se como um período em que se prevalece o humor deprimido e a perda do interesse e prazer pelas atividades, durando, no mínimo, duas semanas. Outros sintomas, como alteração no sono, apetite, peso e atividade psicomotora, diminuição da energia, sentimentos de desamparo ou remorso, dificuldades para se concentrar, pensar e tomar decisões podem também surgir entre algumas pessoas, além de devaneios acerca de mortes, planos e tentativas de suicídio, resultando em incapacidade do indivíduo em realizar suas atividades da vida diária ${ }^{(5)}$. A depressão constitui um fator de risco para o surgimento de doenças crônicas não transmissíveis, doenças cardiovasculares e cerebrovasculares, e fortes evidências apresentam também que está associada à demência, particularmente a doença de Alzheimer. Dessa forma, conhecer os fatores de risco que levam ao adoecimento mental influencia na manutenção da saúde integral do idoso ${ }^{(6,7)}$.

A depressão gera efeitos deletérios que podem ser acrescentados à qualidade de vida da pessoa idosa, o que aumenta os gastos públicos com o sistema de saúde e demanda maior assistência dos profissionais de saúde, que devem estar atentos às manifestações clínicas referentes aos sintomas depressivos para realizar o diagnóstico precoce e evitar maiores impactos na saúde dessa população( ${ }^{(8)}$. A depressão é considerada a principal causa de problemas de saúde e incapacidade funcional no mundo todo, gerando perdas anuais de um trilhão de dólares para o seu tratamento, sendo um grave problema de saúde pública, visto que mais de 300 milhões de pessoas vivem com essa doença ${ }^{(9)}$.

A qualidade de vida da população idosa, em especial a saúde mental, está relacionada diretamente aos acessos às demandas por saúde, habitação, educação, previdência, cultura, lazer, entre outras. A partir desse entendimento, o estado da Paraíba, Brasil, lançou uma iniciativa pioneira por meio da Companhia Estadual de Habitação Popular (CEHAP) e da Secretaria de Estado de Desenvolvimento (SEDH), desenvolvendo um projeto destinado à população idosa que recebe até cinco salários, de ambos os sexos, independente de morar só ou com cônjuge/companheiro também idoso(10).

A Política Nacional de Promoção da Saúde (PNPS) apresenta estratégias para promover a saúde. Além da alimentação saudável, a inclusão social, a promoção de ações, aconselhamento e divulgação de práticas corporais e de atividades físicas, incentivando a melhoria das condições dos espaços públicos, considerando a 
cultura local e incorporando brincadeiras, jogos, danças populares, entre outras práticas, são ações que podem minimizar danos à saúde mental ${ }^{(11)}$.

Levando em consideração que os idosos deste estudo viviam em condição de vulnerabilidade social e que, após a mudança para essa nova residência (em conjunto habitacional), foram disponibilizadas para eles oportunidades antes nunca tidas, como serviços de saúde, centros de convivência, esportes, áreas de lazer, entre outras, contudo eles praticamente não se utilizam desses espaços, permanecendo isolados em seus domicílios muito tempo, surgiu o interesse, por parte dos autores, em realizar esta pesquisa. Dessa forma, buscou-se responder à seguinte questão norteadora: os idosos desta pesquisa apresentam alguma dificuldade, após a mudança de moradia, que esteja causando sintomas de depressão?

Nesse contexto, o estudo tem por objetivo conhecer as dificuldades que o idoso apresenta após mudança de moradia e que influenciam a presença de sintomas de depressão.

\section{MÉTODOS}

Trata-se de um estudo descritivo(12), com abordagem qualitativa ${ }^{(13)}$ utilizando a técnica do Discurso do Sujeito Coletivo ${ }^{(14)}$, realizado no mês de setembro de 2018, com idosos residentes em um conjunto habitacional para idosos localizado na cidade de Cajazeiras, Paraíba, Brasil.

O referido conjunto habitacional é dotado de 40 unidades habitacionais adaptadas para as necessidades da pessoa idosa. Oferece núcleo de assistência e centro de vivências com equipamentos para a convivência social e lazer, utilizado para a realização de diversas atividades de socialização. Faz parte desse espaço a sala multiuso, utilizada para realização de oficinas, entre outras atividades. A pista de caminhada, assim como a academia de saúde, visa proporcionar ao idoso uma melhor qualidade de vida. A horta comunitária tem o objetivo de promover a colaboração e socialização entre os idosos, na perspectiva de que todos façam parte de plantio e da colheita(10).

Em contato prévio com a SEDH, autorizaram-se as visitas ao conjunto habitacional, sendo agendados a data e o horário. A visita ocorreu nas residências, teve duração de todo o turno da tarde, com acompanhamento de uma funcionária da CEHAP. A pesquisadora pôde conversar com os moradores e andar em todos os ambientes do condomínio, momento em que fez os convites para participarem do estudo.

O presente estudo adotou como critérios de inclusão idosos acima de 60 anos e que residissem no conjunto habitacional há seis meses ou mais, sendo critério de exclusão os idosos que possuíam uma doença incapacitante com impedimento de articulação de palavras, em decorrência da necessidade da capacidade discursiva para levantamento das problemáticas a serem debatidas na presente pesquisa.

A amostra contou com 14 idosos após serem adotados os critérios de exclusão e de encerramento, que se deu por saturação de dados ${ }^{(14)}$, utilizando-se a técnica de entrevista semiestruturada, a qual foi composta pela seguinte pergunta: o senhor (a) apresenta dificuldades, após ter se mudado, que podem estar Ihe causando algum sintoma de depressão?

As entrevistas foram agendadas previamente, realizadas de forma individual e em local reservado, em clima harmonioso entre pesquisador e pesquisado, com duração de 30 minutos, em média, cada uma, nas quais os participantes expuseram sua compreensão e seus valores de acordo com a questão norteadora e o objetivo do estudo, sendo gravadas após a permissão dos participantes.

Posteriormente, de posse do material, as gravações foram ouvidas e transcritas para serem analisadas com base no emprego da técnica do DCS, que se trata de uma construção do pensamento coletivo, tendo por objetivo revelar como as pessoas pensam, atribuindo sentidos e posicionamentos sobre determinado assunto ${ }^{(14)}$. Na composição do DSC, empregam-se as figuras metodológicas que traduzem o pensamento coletivo, trazidas nas opiniões individuais, são elas: expressõeschaves $(E C H)$, frações de discursos que compõem a essência do conteúdo do discurso; ideias centrais (IC), que são nomes ou expressões linguísticas impostas ao conteúdo identificado para categorizar o sentido estabelecido para as $\mathrm{ECH}$; ancoragens (AC), expressões de uma dada teoria ou ideologia que o autor do discurso confessa naturalmente; e DSC, uma associação discursiva que reúne fragmentos de distintos discursos individuais unidos pela sua intercompatibilidade ${ }^{(14)}$.

As três IC evidenciadas pelas dificuldades enfrentadas pelos idosos que podem influenciar o surgimento de sintomas depressivos são: IC1: conflitos familiares; IC2: dificuldade nas relações interpessoais; IC3: isolamento social como desencadeador da depressão.

A pesquisa teve início após a aprovação do projeto pelo Comitê de Ética em Pesquisa da Universidade Federal de Campina Grande sob o Parecer n. ${ }^{\circ} 2.890 .996$. O sigilo e o anonimato foram garantidos, mediante a apresentação de um Termo de Consentimento Livre e Esclarecido, fornecido no ato da entrevista. 
Os entrevistados foram identificados com um código alfanumérico representativo de cada entrevistado. Esse código consistiu de uma sequência formada pela letra I (I=Idoso), seguida por um número $(1,2,3 \ldots)$, gerando, por exemplo, o código I1 para o primeiro idoso entrevistado, e assim sucessivamente.

\section{RESULTADOS E DISCUSSÃO}

\section{Análise do Discurso do Sujeito Coletivo (DSC) - idoso}

Será apresentado o DSC a partir das três IC evidenciadas pelas dificuldades enfrentadas pelos idosos residentes em conjunto habitacional que podem influenciar no surgimento de sintomas depressivos, descritas a seguir.

\section{IC1: Conflitos familiares}

A primeira IC aborda os conflitos dos idosos com seus familiares. Participaram quatro idosos: I2, I10, I12 e I13:

"Em casa tem aparecido um monte de coisa de família, filho, filha, isso tudo desgosta a gente, e tem um filho que faz uma coisa que eu não gosto. Às vezes, uma discussão com familiares, você começa a colocar aquilo na cabeça; quem tem família, a gente sempre passa por qualquer coisa, filhos, essas coisas... é assim mesmo." (DSC1)

No DSC1 os idosos relatam os conflitos vivenciados com os seus familiares, em especial com os filhos, que geram afastamento do meio familiar e, consequentemente, surge dentro de si o sentimento de solidão. Há ainda, conforme os discursos, a menção das dificuldades de convivência, resultando em conflitos. Todos esses fatores influenciam para o adoecimento do idoso e, nesse contexto, sintomas depressivos podem surgir. Outras pesquisas também convergem com esse achado, identificando dificuldades no convívio familiar e social dos idosos que incluem limitação de sociabilidade, falta de espaços de lazer, conflitos e abandono familiar, os quais emergem como pontos importantes para o adoecimento do idoso e pode apresentar mais frequentemente sintomas depressivos ${ }^{(15,16)}$.

Os conflitos trazem dificuldades para todos os membros da família, porém os idosos são os que mais sofrem quando vivem em famílias desagregadoras, com pouca manifestação de afeto, compreensão, cumplicidade, e, além disso, muita impaciência, raiva e agressividade, que podem provocar sensação de abandono pelos familiares, os amigos e a falta de apoio para lidar com as situações depressivas ${ }^{(16)}$. O empobrecimento das relações familiares torna o ambiente de convivência insuportável, refletindo na saúde mental do idoso. Por se sentir sem amparo emocional ou por não ter o suporte adequado das pessoas mais próximas, o idoso passa a viver solitário, sendo a porta de entrada para a depressão. Em situações de instabilidade e de confronto, os indivíduos ficam mais sensíveis à desigualdade, talvez por esse motivo os idosos se distanciem da família e busquem morar sozinhos ${ }^{(17,18)}$.

O relacionamento entre gerações na família favorece relações de trocas afetivas, emocionais, de experiência e aprendizagem realizada por pessoas que compartilham crenças, histórias e valores comuns. A inserção do idoso no cenário familiar está relacionada com fatores motivacionais e relacionais, uma vez que a participação em atividades sociais pode aumentar a satisfação com a vida e o envolvimento social ${ }^{(18)}$. Corroborando esse achado, um estudo realizado no estado da Bahia, Brasil, com o objetivo de analisar a relação entre a qualidade de vida e a sintomatologia depressiva em idosos que vivem no contexto doméstico, mostra que os sintomas depressivos têm um grande impacto nas condições de vida do indivíduo, refletindo condições caóticas na saúde da população idosa. Muitas vezes, os idosos, por serem esquecidos por seus familiares, estão à margem da sociedade, sem apoio emocional e psicológico, o que dificulta o estabelecimento de relações afetivas, familiares e sociais tão importantes para o ser humano viver na sociedade ${ }^{(18)}$.

Os conflitos e problemas familiares envolvem significados construídos no decorrer da existência e se associam a outros fatores, a exemplo das manifestações de pensamentos e tentativas de suicídio em pessoas idosas, bem como sinalizam para os familiares ideações e gestos introspectivos, de isolamento, de desesperança e de profundo sofrimento emocional ${ }^{(16)}$. Os arranjos familiares são imprescindíveis para a manutenção da saúde do idoso. Por meio da confiança, da empatia, do amor, da escuta e do apoio às atividades diárias, o idoso se sente acolhido e tem suas necessidades supridas de forma integral, servindo de suporte para a superação de angústias, ansiedades e sentimentos de impotência que possam surgir nessa nova fase da vida ${ }^{(19)}$.

Portanto, a família deve ser ponto de cuidado e apoio para o idoso, tanto em situação de saúde quanto de doença, acompanhando, avaliando e pedindo ajuda aos profissionais de saúde. Cuidar de um idoso é, muitas vezes, um grande desafio, entretanto os vínculos afetivos familiares são fundamentais para a manutenção da autonomia e qualidade de vida, atuando para a prevenção da depressão. 


\section{IC2: Dificuldade nas relações interpessoais}

A segunda IC trata das dificuldades enfrentadas pelo idoso no que se refere às relações e aos convívios interpessoais com pessoas da mesma geração. Participaram sete idosos: I1; I2; 14; 16; 19; I10 e I13:

"Aqui, por ser uma comunidade, deveria ter mais união, é um povo que não se enturma, né?! O que se enturma é para conversar coisa que não bate com a idade da gente, aí eu não faço parte. Aqui, em vez de interagirmos, no conjunto, conversando como os outros, que isso melhora, não, cada um na sua casa, ninguém visita a casa da gente, não, se puder falar mal do meu vizinho é isso que eu vou fazer. Se você se arruma, vai sair, tem uma vizinha que tem inveja do que você usa, ela fica olhando, você percebe que as pessoas tem um olhão gordo em cima de você e você já começa a pensar coisa com coisa, isso tudo é facilidade para a depressão. Uma vez já me passou dos limites por causa dos fuxicos que me fizeram e eu fiquei muito nervoso, porque a má palavra incomoda qualquer pessoa, a pessoa se sente magoada. Ninguém é melhor do que outro, aqui são mágoas, uns se fecharam nas suas mágoas demais, uns tem rancor e ódio, e distribui ao vento." (DSC2)

Os autores perceberam pelos discursos que o espaço físico do conjunto habitacional é composto por moradias individuais ou para casais. Dessa forma, os idosos podem manter sua individualidade, ao mesmo tempo eles também podem exercitar o convívio social, pois existe um centro de convivência comum a todos os moradores, o que permite o desenvolvimento de atividades de lazer e em grupo. No DSC2, os participantes relatam as dificuldades enfrentadas no convívio com os seus vizinhos, mostrando que as relações com os outros nem sempre são recíprocas, e o comportamento pode causar antipatia entre os residentes. Dessa forma, essa realidade pode fragilizar a pessoa emocionalmente e desencadear conflitos interpessoais.

O conflito ocorre quando há diferença de valores e ideias divergentes entre pessoas ou grupos, alterando os relacionamentos. Quando vivenciado, as ações de um dos conflitantes são entendidas como boas e as do outro, como más. Os conflitos interpessoais consistem em situações de interação social de confronto, desacordo e frustração, as quais provocam efeitos negativos na vida das pessoas. Sendo assim, o conflito pertence à realidade dos seres humanos e são essenciais para o desenvolvimento pessoal e social, porém é necessário encontrar formas de melhor resolvê-los para evitar o seu agravamento ${ }^{(20)}$.

Ao adentrar no conjunto habitacional para morar, o idoso se depara com pessoas nunca vistas antes, o que pode levá-lo a isolar-se pela percepção de não pertencimento a esse local e sentimento de decepção diante do julgamento estabelecido pelo seu vizinho e, consequentemente, a não manter um relacionamento interpessoal necessário para o convívio em comunidade pela realidade que lhe é apresentada ${ }^{(20)}$.

Portanto, vale ressaltar que o envelhecimento é permeado por acúmulos de perdas simbólicas e reais, resultando em relacionamentos emocionais enfraquecidos e na vida social diminuída. Essa sobrecarga pode gerar raiva, angústia, frustração e tristeza. Esses sentimentos negativos podem ser desfavoráveis à manutenção da saúde mental dos idosos. É necessário proporcionar a essa população atividades diárias que possam ocupar suas mentes e dar sentido à sua existência(4).

Por vezes, o idoso se vê cercado por outras pessoas com os quais não pode estabelecer contato pessoal, e assim se manifesta um convívio de hostilidade. Portanto, é de extrema importância incentivar os laços afetivos entre os idosos do condomínio, pois o fato de estabelecerem relações saudáveis com o próximo garante ao idoso companheirismo, amor e respeito, sentimentos fundamentais para contribuir na superação dos sentimentos depressivos ${ }^{(21)}$.

A interação social com outros indivíduos da mesma idade pode ser uma oportunidade de criação de novos vínculos e laços de amizade e companheirismo, amenizando a solidão. Desse modo, se faz necessária a interação dos idosos com outras pessoas e o envolvimento social, os quais são essenciais para manter a funcionalidade e o desenvolvimento do indivíduo. As relações sociais interpessoais são importantes fontes de suporte social, estimulam a mente e o pensamento, tendo múltiplos efeitos benéficos sobre a saúde e bem-estar, contribuindo para a melhoria da qualidade de vida ${ }^{(21)}$.

\section{IC3: Isolamento social como desencadeador da depressão}

A terceira IC discute a problemática do isolamento social como gerador de adoecimento mental. Neste DSC, houve a participação dos seguintes pesquisados: I6; I9; I10; I11; I12 e I13:

"Sei lá é uma solidão, às vezes não quer ver gente e se isola do mundo, na minha casa não anda ninguém, sou uma pessoa que vivo só, a solidão aqui é muito grande, eu mesmo não tenho família, porque meus filhos moram tudo fora, a distância dos meus filhos também me mata, aí aqui tudo é distante. É a pessoa estando 
sozinha em casa, os filhos tudo longe, aí fico só bolando, bolando, até chegar o sono e é porque eu tomo o remédio para dormir. Eu sempre fui uma pessoa assim, da sociedade, de tá em festa, de tá em tudo, onde morava eu tinha pessoa para conversar de noite, eu passava a noite conversando, ia pra igreja, assistia a missa quando vinha sentava na calçada para conversar um pedacinho, e aqui nada disso tem, passei a viver isolado, a depressão passou por aí, viu!" (DSC3)

Percebeu-se, no DSC3 deste estudo, que os idosos demonstraram durante a entrevista a sensação de solidão, em decorrência da dificuldade em ir ao encontro dos amigos ou receber visitas, a família que mora longe e o vê ocasionalmente. $\mathrm{O}$ fato de residir em um conjunto habitacional para idosos, localizado distante do centro comercial da cidade e muitos não possuem meios de transporte para a sua locomoção, com isso, os idosos ficam, por vezes, isolados em seus lares, deixando de manter suas relações sociais.

A companhia de familiares, o envolvimento em atividades de lazer e participação comunitária pode ter um efeito considerável sobre o estado de saúde psicológica dos idosos com menor probabilidade de desenvolver emoções depressivas. Os idosos que vivem sozinhos são propensos aos sentimentos de solidão e isolamento, o que pode piorar uma depressão. No entanto, o efeito protetor da participação social deriva principalmente do apoio social fatores de proteção podem melhorar a resiliência dos idosos e permitir que eles enfrentem dilemas de maneira rápida e eficaz quando confrontados com episódios de solidão, bem como restaurar seu estado de saúde e viver uma vida satisfatória ${ }^{(22)}$.

No DSC3, os idosos relatam a má qualidade do sono relacionada ao estado de solidão. Sobre esses achados, estudos anteriores realizados com população chinesa e holandesa, que associaram a relação entre qualidade do sono e depressão, evidenciaram que os resultados indicaram que fatores demográficos, familiares, de estilo de vida e sociais afetavam distúrbios do sono, e ainda revelaram a prevalência de má qualidade do sono associados com problemas de saúde mental, incluindo a depressão ${ }^{(23,24)}$.

O isolamento social pode contribuir para uma condição potencializadora da depressão, pois a possibilidade de sair se torna difícil, incluindo visitar filhos e amigos, frequentar grupos comunitários e ir à igreja, entre outras atividades cotidianas. Assim, deixam de exercer atividades antes vivenciadas com prazer, sendo privado de convívio social, tornando o seu convívio social limitado. O isolamento social implica no domínio físico e psicológico, e pode ser considerado como um importante determinante para a depressão. Em função disso, priva-se do convívio social e tende a sair menos, consequentemente empobrecendo o conhecimento adquirido no contato social e afetando as atividades de vida diária( ${ }^{(18)}$. O apoio social incide na percepção de demonstração de afeto, confiança e ajuda por seus familiares e vizinhos. Além disso, exerce tem impactos benéficos sobre a qualidade de vida, autoestima e previne o surgimento da sintomatologia depressiva. O convívio social possibilita comunicar e compartilhar os problemas do envelhecimento com as pessoas com quem os idosos vivem e descarregar emoções negativas. Nesse sentido, ter alguém próximo pode ajudar a enfrentar os desafios do envelhecimento ${ }^{(25,26)}$.

Portanto, o isolamento social causa sentimentos de solidão e, por consequência, o sofrimento mental. Desse modo, é importante estabelecer relações sociais de troca para a formação de um vínculo afetivo, sendo este preditor significativo para a aquisição de novos saberes, uma vez que os idosos continuam se desenvolvendo mentalmente à medida que vão envelhecendo. Portanto, o apoio social contribui para a saúde mental, influenciando na redução de níveis de depressão nos idosos.

O presente estudo deixa clara a relevância de promover atividades que incentivem a participação dos idosos, levando-os ao convívio e interação social entre eles, a fim de que conservem resguardados os sentimentos ligados à vontade de viver. Os profissionais de saúde devem estar preparados para identificar os sinais de depressão no idoso, tomando as providencias cabíveis para cada caso identificado. Este estudo evidencia que a promoção da saúde pode ser exposta como o compromisso dos gestores e trabalhadores da saúde para compreender a determinação social da saúde, do adoecimento, da morte e dos diferentes agravos na vida dos indivíduos, a partir da ação voluntária e ativa da população no diagnóstico das necessidades sociais locais, promovendo a redução das iniquidades ${ }^{(27)}$.

A Política Nacional de Saúde da Pessoa Idosa (PNSPI) indica a proteção à vida e à saúde do idoso, cujo principal acometimento é a perda da capacidade funcional, reafirmando a necessidade da abrangência acerca do processo de envelhecimento. A PNSPI traz em suas diretrizes a promoção do envelhecimento saudável, a sustentação da capacidade funcional e a proteção às necessidades de saúde do idoso(28)

As limitações desta investigação dizem respeito ao fato de os participantes terem sido selecionados de forma intencional e em apenas um conjunto habitacional para idosos, o que não permite generalizar os resultados. Diante disso, os autores sugerem a realização de outros estudos, que abarquem uma maior dimensão territorial e que permitam reconhecer outros fatores que possam estar relacionados com o surgimento da depressão nos idosos. 


\section{CONSIDERAÇÕES FINAIS}

No presente estudo, podem-se perceber sentimentos que podem resultar no surgimento da sintomatologia depressiva, como sentimento de solidão, dificuldades de convivência e isolamento social, apesar do programa habitacional oferecer assistência à saúde e espaços de convivência para a interação social e lazer, que podem não ser suficientes para suprir as necessidades psicológicas e emocionais dos idosos avaliados.

Os participantes desta pesquisa possuem uma rede social escassa e poucas relações significativas. Além disso, retratam ter dificuldades nas relações interpessoais e conflitos com seus familiares, cujo aspecto pode prejudicar sua saúde mental, tendo com agravante o fato de residirem sozinhos, podendo levar à depressão.

Nesse sentido, torna-se pertinente a utilização de ações em saúde dentro do conjunto habitacional que contribuam para a detecção precoce dos sintomas depressivos nos idosos, de modo que fortaleçam o vínculo e a participação mais assídua da família e de vizinhos, dando suporte às suas necessidades, visto que a melhora no relacionamento familiar e social poderá contribuir para a saúde deles.

\section{CONFLITOS DE INTERESSE}

Os autores declaram não haver conflitos de interesses de nenhum tipo para a publicação e divulgação deste artigo.

\section{CONTRIBUIÇÕES}

Jovelina Fernandes dos Santos e Marcelo Costa Fernandes contribuíram com a elaboração e delineamento do estudo; a aquisição, análise e interpretação de dados; e a redação e/ou revisão do manuscrito. Mayara Evangelista de Andrade e Joyce Wadna Rodrigues de Souza contribuíram com a aquisição, análise e interpretação de dados; e a redação e/ou revisão do manuscrito. Petra Kelly Rabelo de Sousa Fernandes e Ariane Moreira Coelho contribuíram com a aquisição, análise e interpretação de dados.

\section{REFERÊNCIAS}

1. Organização Mundial da Saúde. Relatório mundial de desenvolvimento e saúde [Internet]. Brasília: OMS; 2015 [acesso em 2019 Nov 11]. Disponível em: http://sbgg.org.br/wp-content/uploads/2015/10/OMSENVELHECIMENTO-2015-port.pdf

2. Instituto Brasileiro de Geografia e Estatística. Projeto de população no Brasil e unidades de federação por sexo e idade para o período de 2000 a 2030 [Internet]. Rio de Janeiro: IBGE; 2015 [acesso em 2019Nov 11]. Disponível em: https://www.ibge.gov.br/estatisticas/sociais/populacao/9109-projecao-da-populacao.html

3. Meneguci J, Meneguci CAG, Moreira MM, Pereira KR, Tribess S, Sasaki JE, et al. Prevalência de sintomatologia depressiva em idosos brasileiros: uma revisão sistemática com metanálise. J Bras Psiquiatr [Internet]. 2019 [acesso em 2020 Abr 18];68(4):221-30. Disponível em: https://www.scielo.br/scielo. php?script=sci_arttext\&pid=S0047-20852019000400221\#B1

4. Cordeiro RC, Santos RC, Araújo GKN, Nascimento NM, Souto RQ, Ceballos AGC, et al. Mental health profile of the elderly community: a cross-sectional study. Rev Bras Enferm [Internet]. 2020 [acesso em 2020 Maio 10];73(1):e20180191. Disponível em: http://www.revenf.bvs.br/scielo.php?script=sci_arttext\&pid=S003471672 020000100172\#B31

5. American Psychiatric Association. Manual Diagnóstico e Estatístico dos Transtornos Mentais - DSM-5 [Internet]. Porto Alegre: Artmed; 2014 [acesso em 2020 Ago 22]. Disponível em: https://aempreendedora.com. br/wp-content/uploads/2017/04/Manual-Diagn\%C3\%B3stico-e-Estat\%C3\%ADstico-de-Transtornos-MentaisDSM-5.pdf

6. Dias NS, Barbosa IG, Kuang W, Teixeira AL. Distúrbios depressivos em idosos e demência: uma atualização. Dement Neuropsicol [Internet]. 2020 [acesso em 2020 Maio 10];14(1):1-6. Disponível em: http://www.scielo. br/scielo.php?script=sci_arttext\&pid=S1980-57642020000100001\&lng=en

7. Silva AR, Sgnaolin V, Nogueira EL, Loureiro F, Engroff P, Gomes I. Doenças crônicas não transmissíveis e fatores sociodemográficos associados a sintomas de depressão em idosos. J Bras Psiquiatr [Internet]. 2017 [acesso em 2020 Maio 10];66(1):45-51. Disponível em: http://www.scielo.br/scielo.php?script=sci_ arttext\&pid=S0047-20852017000100045\&lng=en 
8. Souza JEV, Brito SA, Rosa RS, Boery EN, Boery RNSO. Impacto dos fatores associados à sintomatologia depressiva na saúde de idosos em hemodiálise. Enfermería Actual Costa Rica [Internet]. 2018 [acesso em 2020 Maio 13];(35):159-72. Disponível em: http://www.scielo.sa.cr/scielo.php?script=sci_arttext\&pid=S140945682018000200159\&lng=en

9. Organização Mundial Da Saúde. Com depressão no topo da lista de causas de problemas de saúde, OMS lança a campanha "Vamos conversar" [Internet]. 2017 [acesso em 2020 Ago 22]. Disponível em: https://www. paho.org/bra/index.php?option=com_content\&view=article\&id=5385:com-depressao-no-topo-da-lista-decausas-de-problemas-de-saude-oms-lanca-a-campanha-vamos-conversar\&ltemid=839

10. Companhia Estadual de Habitação Popular da Paraíba. Programa: cidade madura [Internet]. 2014 [acesso em 2020 Ago 22]. Disponível em: https://paraiba.pb.gov.br/diretas/secretaria-de-desenvolvimento-humano/ programas/condominio-cidade-madura

11. Ministério da Saúde (BR), Secretaria de Vigilância em Saúde, Secretaria de Atenção à Saúde. Política Nacional de Promoção da Saúde: anexo I da Portaria de Consolidação n 2, de 28 de setembro de 2017, que consolida as normas sobre as políticas nacionais de saúde do SUS [Internet]. Brasília: Ministério da Saúde; 2018 [acesso em 2020 Ago 22]. Disponível em: http://bvsms.saude.gov.br/bvs/publicacoes/politica_nacional_ promocao_saude.pdf

12. Triviños ANS. Introdução à Pesquisa em ciências sociais: a pesquisa qualitativa em educação - o positivismo, a fenomenologia, o marxismo. $5^{\mathrm{a}}$ ed. São Paulo: Atlas; 2009.

13 Minayo MCS. O desafio do conhecimento: pesquisa qualitativa em saúde. 10ª ed. São Paulo: HucitecAbrasco; 2007.

14. Lefèvre $F$, Lefèvre $A M C$. $O$ discurso do sujeito coletivo: um novo enfoque em pesquisa qualitativa (desdobramentos). $2^{\mathrm{a}}$ ed. Caxias do Sul: Educs; 2005.

15. Mendes-Chiloff CL, Lima MCP, Torres AR, Santos JLF, Duarte YO, Lebrão ML, et al. Depressive symptoms among the elderly in São Paulo city, Brazil: prevalence and associated factors (SABE Study). Rev Bras Epidemiol [Internet]. 2018 [acesso em 2019 Ago 1];21(Suppl2):e180014. Disponível em: http://www.scielo.br/ scielo.php?script=sci_arttext\&pid=S1415-790X2018000300411\&lng=pt

16. Silva RM, Mangas RMN, Figueiredo AEB, Vieira LJES, Sousa GS, Cavalcanti AMTS, et al. Influências dos problemas e conflitos familiares nas ideações e tentativas de suicídio de pessoas idosas. Ciênc Saúde Colet [Internet]. 2015 [acesso em 2019 Nov 4];20(6):1703-10. Disponível em: http://www.scielo.br/scielo. php?script=sci_arttext\&pid=S1413-81232015000601703\&lng=en

17. Oliveira MCGM, Salmazo-Silva H, Gomes L, Moraes CF, Alves VP. Idosos em domicílios multigeracionais: composição familiar, satisfação com a vida e envolvimento social. Estud Psicol (Campinas) [Internet]. 2020 [acesso em 2020 Maio 04];37:e180081. Disponível em: http://www.scielo.br/scielo.php?script=sci_ arttext\&pid=S0103-166X2020000100800\&Ing=en\&nrm=iso

18. Santos RV, Souza RR, Cruz SGJ, Santos RÍJ, Cassotti CA. Qualidade de vida e depressão em domicílios no contexto doméstico. Enfermería Actual Costa Rica [Internet]. 2018 [acesso em 2020 Maio 12];(34):53-66. Disponível em: http://www.scielo.sa.cr/scielo.php?script=sci_arttext\&pid=S140945682018000100053\&lng=en.atualizado

19. Camatta MW, Tocantins FR, Schneider JF. Ações de saúde mental na Estratégia Saúde da Família: expectativas de familiares. Esc Anna Nery [Internet]. 2016 [acesso em 2019 Nov 14];20(2):281-8. Disponível em: ttp://www.scielo.br/scielo.php?script=sci_arttext\&pid=S1414-81452016000200281\&lng=en

20. Bruinsma JL, Beuter M, Leite MT, Hildebrandt LM, Venturini L, Nishijima RB. Conflitos entre idosas institucionalizadas: dificuldades vivenciadas pelos profissionais de enfermagem. Esc Anna Nery [Internet]. 2017 [acesso em 2019 Nov 11];21(1):e20170020. Disponível em: http://www.scielo.br/scielo.php?script=sci_ arttext\&pid=S1414-81452017000100220\&Ing=en

21. Lima PV, Valença TDC, Reis LA. Repercussões psicossociais da dependência funcional no cotidiano de idosos longevos. Rev Kairós [Internet]. 2017 [acesso em 2019 Nov 29];20(2):293-309. Disponível em: https:// revistas.pucsp.br/index.php/kairos/article/view/35061/24003

22. Li YT, Tung TH. Efeitos de fatores de proteção no estado depressivo de idosos em Taiwan. Medicina 
[Internet]. 2020 [acesso em 2020 Maio 11]:99(1):e18461. Disponível em:https://journals.Iww.com/md-journal/ FullText/2020/01030/Effects_of_protective_factors_on_the_depressive.14.asp

23. Rian JGP, Neijenhof ED, Hannie CC, Julia FB, Margot WMW, Richard COV, et al. Correlatos de distúrbios do sono em idosos deprimidos: estudo holandês sobre depressão em idosos (NESDO). Envelhecimento Saúde Met [Internet]. 2018 [acesso em 2020 Maio 11];22(2):233-8. Disponível em: https://www.tandfonline.com/doi/ abs/10.1080/13607863.2016.1247421?journalCode=camh20

24. Ru-Qing L, Michael SB, Qi-Zhen W, Zhi-Zhou H, Zhengmin Q, Katherine A, et al. Associação entre sintomas depressivos e má qualidade do sono entre as etnias Han e Manchu em uma grande população rural e chinesa. Plos One [Internet]. 2019 [acesso em 2020 Maio 11];14(12):e0226562. Disponível em: https:// journals.plos.org/plosone/article?id=10.1371/journal.pone. 0226562

25. Salazar-Barajas ME, LilloCrespo M, Hernández CPL, Villarreal RMLÁ, Gallegos CEC, Gómez MMV, et al. Factors contributing to active aging in older adults, from the Framework of Roy's Adaptation Model. Invest Educ Enferm [Internet]. 2018 [acesso em 2019 Ago 11];36(2). Disponível em: https://www.ncbi.nlm.nih.gov/ pubmed/30148942

26. Baptista MN, Cunha FA, Marques MAN. Evidências de estrutura interna da Escala Baptista de Depressão - Versão Idoso (EBADEP-ID). Rev Psicol Pesqui [Internet]. 2019 [acesso em 2019 Ago 11];13(1):10-10. Disponível em: http://ciberindex.com/index.php/ec/article/view/e10739

27. Ministério da Saúde (BR), Secretaria de Vigilância à Saúde, Secretaria de Atenção à Saúde. Política Nacional de Promoção da Saúde: PNPS: revisão da Portaria MS/GM n. ${ }^{\circ}$ 687, de 30 de março de 2006. Brasília: Ministério da Saúde; 2014.

28. Silva JAC, Almeida MHM. Orientações políticas e prática profissional em instituições de longa permanência para idosos. Est Interdiscipl Envelhecim. 2013;18(1):119-35.

\section{Endereço do primeiro autor:}

Jovelina Fernandes dos Santos

Universidade Federal de Campina Grande - Unidade Acadêmica de Enfermagem

Rua Sérgio Moreira de Figueiredo, s/n

Bairro: Casas Populares

CEP: 58900-000 - Cajazeiras - PB - Brasil

E-mail: jove_lina@live.com

\section{Endereço para correspondência:}

Marcelo Costa Fernandes

Universidade Federal de Campina Grande - Unidade Acadêmica de Enfermagem

Rua Sérgio Moreira de Figueiredo, s/n

Bairro: Casas Populares

CEP: 58900-000 - Cajazeiras - PB - Brasil

E-mail: celo_cf@hotmail.com

Como citar: Santos JF, Andrade ME, Souza JWR, Coelho AM, Fernandes PKRS, Fernandes MC. Impacto de fatores associados à sintomatologia depressiva na saúde de idosos após mudança habitacional. Rev Bras Promoç Saúde. 2020;33:10961. 